\title{
Atypical focal cortical dysplasia in a patient with Cowden syndrome
}

\author{
KM Cheung *, CW Lam, YK Chan, WK Siu, L Yong
}

\section{A B S T R A C T}

A macrocephalic girl presented with generalised epilepsy due to focal cortical dysplasia. She later developed multiple hamartomatous lesions and was diagnosed to have Cowden syndrome. The diagnosis was confirmed by identification of a novel frameshift mutation in the PTEN gene of the patient.

Hong Kong Med J 2014;20:165-7

DOI: $10.12809 / \mathrm{hkmj} 133863$

${ }^{1}$ KM Cheung *, MB, ChB

\author{
${ }^{4} \mathrm{CW}$ Lam, MB, ChB, PhD \\ ${ }^{2}$ YK Chan, MB, BS \\ ${ }^{5}$ WK Siu, MB, BS \\ ${ }^{3} \mathrm{~L}$ Yong, $\mathrm{MB}, \mathrm{ChB}$ \\ Department of Paediatrics \\ Department of Medicine and Geriatrics \\ ${ }^{3}$ Department of Surgery \\ Caritas Medical Centre, Shamshuipo, Hong Kong \\ ${ }^{4}$ Department of Pathology, The University of Hong Kong, Pokfulam, Hong \\ Kong \\ ${ }^{5}$ Kowloon West Cluster Laboratory Genetic Service, Chemical Pathology \\ Laboratory, Department of Pathology, Princess Margaret Hospital, \\ Laichikok, Hong Kong \\ * Corresponding author: jennykmcheung@gmail.com
}

\section{Case report}

A 10-year-old Chinese girl presented to a paediatric clinic with epilepsy. She had normal intelligence and social interaction ability, and no relevant family history. She had been having recurrent sleep seizures, with generalised twitching of all four limbs, cyanosis, up-rolling of eyeballs, drooling, and urinary incontinence. Her head circumference was $61 \mathrm{~cm}$ $(5 \mathrm{~cm}>$ the 97 th percentile). Physical examination was otherwise normal. The electroencephalogram showed an abnormal focus at the right temporooccipital region. Goldmann perimetry revealed no abnormality. Magnetic resonanceimaging (MRI) with contrast showed pachygyria (total loss of sulcation) with hyperplastic white matter and disorganisation of the grey and white matters in the right occipital lobe. A $2.5 \mathrm{~cm} \times 1.8 \mathrm{~cm}$ T2 hyperintense area around the right occipital horn was consistent with gliosis. The right occipital lobe was mildly enlarged. Repeated MRI 5 and 7 years after presentation showed no interval changes. Her findings were compatible with focal cortical dysplasia involving the right occipital lobe (Fig 1). The epilepsy was under good control with carbamazepine treatment. She developed a goitre at the age of 16 years, but was euthyroid and ultrasonography showed a multinodular goitre. Hypertrichosis was noted when she was 17 years old. Multiple tiny papules were noted at the perinasal region, of which the patient regarded as coarse skin. At the age of 19 years, she was incidentally found to have iron deficiency anaemia (haemoglobin $96 \mathrm{~g} / \mathrm{L}$ [reference range, 117-149 g/L], mean corpuscular volume $68.5 \mathrm{fL}$ [82-97 fL], serum iron $2 \mu \mathrm{mol} / \mathrm{L}$ [5.0$30.4 \mu \mathrm{mol} / \mathrm{L}$ ], total iron binding capacity $77.1 \mu \mathrm{mol} / \mathrm{L}$
[44.8-76.0 $\mu \mathrm{mol} / \mathrm{L}])$. She had no gastro-intestinal symptoms, but did receive iron supplements.

She had a left hemithyroidectomy at the age of 22 years for increasing size of a dominant left-sided thyroid nodule that expanded from $1.7 \times 1.4 \times 0.8$ cm to $3.6 \times 2.9 \times 4.2 \mathrm{~cm}$ over 10 months. Fine-needle aspiration showed lymphocytic thyroiditis, and excisional biopsy revealed adenomatous hyperplasia. At the age of 23 years, enlargement of a thyroid nodule in the right thyroid lobe $(3 \mathrm{~cm}$ in diameter) was noted; fine-needle aspiration suggested it was an adenomatous nodule. Total thyroidectomy was performed, and excisional biopsy revealed an atypical nodule with atypical enlarged vesicular nuclei and small distinct nucleoli. The patient also developed a 3-cm scalp papilloma, shown by excisional biopsy to be fibrous papule. At the age of 24 years, she also experienced coffee ground vomiting; oesophagogastroduodenoscopy showed diffuse glycogen deposits at the lower oesophagus and multiple gastric polyps. Polypectomy yielded lymphoid hyperplasia, and oesophageal mucosa biopsy was reported as showing glycogenic acanthosis.

In view of her multiple benign tumours, the possibility of a hamartomatous polyposis syndrome was suspected. Subsequent clinical examination yielded multiple papillomas over the face and tongue, but there was no pigmentation of the lips. These mucocutaneous features were pathognomonic criteria of Cowden syndrome. Notably, macrocephaly, thyroid adenoma, gastrointestinal hamartomas (oesophageal glycogenic acanthosis and gastric polyps), and skin fibromas 


\section{Cowden綜合症患者的非典型局部腦皮質 發育異常}

\section{張嘉明、林青雲、陳耀奇、蕭慧君、翁立}

一名大頭女孩因局部腦皮質發育異常而出現全身性癲瘉。她後來出現 多個缺陷瘤性病變並透過檢測PTEN基因發現一個新型移碼突變, 從 而確診Cowden綜合症。

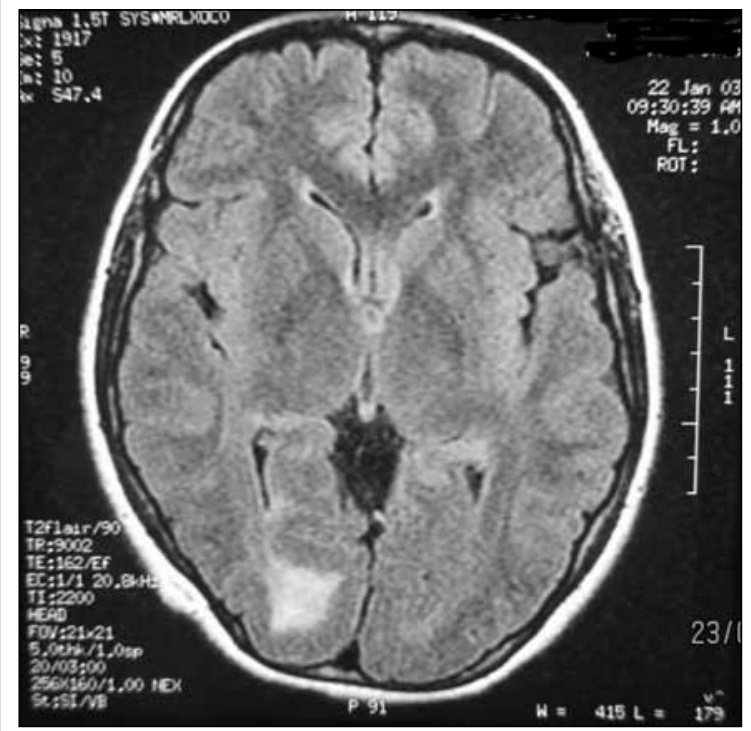

FIG. I Magnetic resonance imaging flare sequence showing focal cortical dysplasia at right occipital lobe

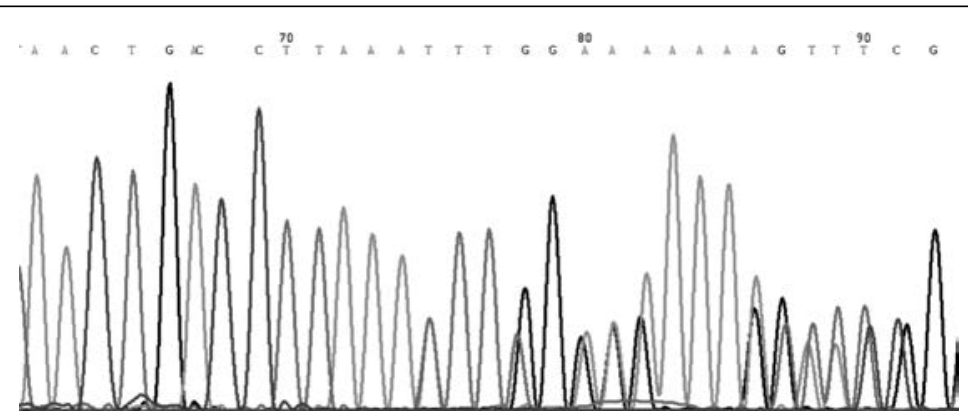

FIG. 2 Mutational analysis for patient with Cowden syndrome NM_0003 I 4.4(PTEN_V00 I):c. I 023del

c. I $023 \mathrm{del}$ in exon 8 of the PTEN gene shown in the anti-sense direction shift starting at codon Phe341. The new reading frame ends in a stop codon 2 position downstream (NM_000314.4(PTEN_i001):p.(Phe341Leufs*3). This mutation was not detected in the mother. The patient's father was deceased 10 years earlier due to lung cancer, but he did not have macrocephaly or a history of any other tumours.

\section{Discussion}

Cowden syndrome was first described by Lloyd and Dennis in $1963 .{ }^{1}$ It is characterised by macrocephaly, mucocutaneous lesions, acral (extremity/limb) keratosis, papillomatous papules, and high risk of development of cancer in the breast, thyroid, and endometrium. It is a rare autosomal dominant disease, with an estimated prevalence of 1 in 1000000 to 250000 based on genetic identification. ${ }^{2}$ Lesions can occur in tissues derived from all three embryonic germ cell layers. The subtle and variable clinical manifestations contribute to the difficulty in making a clinical diagnosis. In 1996, the international Cowden Consortium identified germline PTEN (phosphatase and tensin homologue on chromosome 10) mutations as a cause of Cowden syndrome. ${ }^{2}$ This is a tumour suppressor gene encoding a major lipid phosphatase that functions in the phosphoinositide 3-kinase signalling cascade. ${ }^{3}$ It regulates cellular processes crucial for normal development, including cell proliferation, soma growth, cell death, and cell migration. ${ }^{4}$ The importance on PTEN mutations in making a diagnosis, genetic counselling, and clinical surveillance for the development of malignancies is well recognised. Apart from cancer susceptibility, the PTEN mutation was also implicated as candidate gene in developmental disorder like autism and mental retardation. ${ }^{4}$

Our patient was first suspected to have Cowden syndrome because of the interesting endoscopic findings, as multiple gastric polyps are rarely encountered in young adults. Patients with such polyps should be examined for various genetic syndromes associated with gastro-intestinal polyps, including Peutz-Jeghers syndrome, Cowden syndrome, and Cronkhite-Canada syndrome. ${ }^{5}$ Histology shows Helicobacter pylori-negative, nonspecific lymphoid hyperplasia. Diffuse oesophageal glycogenic acanthosis has seldom been seen in young adults. The concurrence of oesophageal glycogenic acanthosis and multiple gastric polyps is associated with Cowden syndrome. ${ }^{6-8}$

Adult-onset Lhermitte-Duclos disease (LDD), which presents clinically with progressive cerebellar sign and increased intracranial pressure, is also a feature. A dysplastic cerebellar gangliocytoma is now considered to be one of the central nervous system (CNS) pathognomonic criteria by the revised Cowden Syndrome Consortium. The other overt CNS manifestations of Cowden syndrome included 
macrocephaly, autism, developmental delay, brain tumour, and LDD. The unique feature in our patient was the presentation with generalised epilepsy in childhood and the identification of focal cortical dysplasia in the right occipital region. To our knowledge, such brain MRI imaging has not been described previously in Cowden syndrome. ${ }^{9}$ Apart from regulating cell growth, the PTEN gene also plays a role in cell migration. It interacts with focal adhesion kinase, which results in the inhibition of cell migration and spread. Focal cortical dysplasia is a kind of neuronal migration disorder. Our patient was noted to have a right occipital focal cortical dysplasia and right megalencephaly. These features suggest CNS manifestations of the PTEN mutation. Inclusion of this feature in Cowden syndrome may facilitate early diagnosis.

Cowden syndrome represents a late-onset phenotype of the PTEN mutation. Early presentation of PTEN mutations include Bannayan-RileyRuvalcaba syndrome and autism spectrum disorder with macrocephaly. Bannayan-Riley-Ruvalcaba syndrome is a congenital disorder characterised by macrocephaly, hamartomatous intestinal polyps, lipomas, and pigmented macules on the penis. To our knowledge, our patient represents a new PTEN mutation phenotype, with macrocephaly and focal cortical dysplasia at the occipital region and subsequent full-blown presentation of Cowden syndrome.

In conclusion, we believe we have identified a new phenotype of Cowden syndrome and a new PTEN indel mutation. This PTEN mutation appears to cause megalencephaly, epilepsy, focal cortical dysplasia in the occipital region in childhood, and multiple hamartomatous lesions in late adolescence and early adulthood. The inclusion of focal cortical dysplasia in the occipital region as a CNS feature of the PTEN mutation could facilitate early diagnosis of PTEN mutation syndromes, and clinicians to undertake early surveillance for possible malignancies. In the latest published prospective study of the Ohio cohort of patients with germline PTEN mutation, the penetrance of breast cancer was found to begin at around the age of 30 years rising to an estimated $85 \%$ lifetime risk. ${ }^{10}$ The lifetime risk of breast cancer in females with PTEN mutations was even higher than the best estimates for individuals with BRCA1 or BRCA2 mutations. ${ }^{11}$ The PTENrelated endometrial cancer risk begins at the age of 25 years rising to $30 \%$ by the age of 60 years. ${ }^{10}$ The thyroid cancer risk begins at birth and continues lifelong. ${ }^{10}$ Risks of colorectal and kidney cancers begin at around the age of 40 years, with a lifetime risk of $9 \%$ and $34 \%$, respectively. ${ }^{10}$ The earliest reported age of onset of melanoma was in a 3-yearold patient. ${ }^{10}$

\section{References}

1. Lloyd KM 2nd, Dennis M. Cowden's disease. A possible new symptom complex with multiple system involvement. Ann Intern Med 1963;58:136-42.

2. Farooq A, Walker LJ, Bowling J, Audisio RA. Cowden syndrome. Cancer Treat Rev 2010;36:577-83.

3. Shen WH, Balajee AS, Wang J, et al. Essential role for nuclear PTEN in maintaining chromosomal integrity. Cell 2007;128:157-70.

4. Orrico A, Galli L, Buoni S, Orsi A, Vonella G, Sorrentino $\mathrm{V}$. Novel PTEN mutations in neurodevelopmental disorders and macrocephaly. Clin Genet 2009;75:195-8.

5. Hizawa K, Iida M, Matsumoto T, et al. Gastrointestinal manifestations of Cowden's disease. Report of four cases. J Clin Gastroenterol 1994;18:13-8.

6. McGarrity TJ, Wagner Baker MJ, Ruggiero FM, et al. GI polyposis and glycogenic acanthosis of the esophagus associated with PTEN mutation positive Cowden syndrome in the absence of cutaneous manifestations. Am J Gastroenterol 2003;98:1429-34.

7. Vasovcak P, Krepelova A, Puchmajerova A, et al. A novel mutation of PTEN gene in a patient with Cowden syndrome with excessive papillomatosis of the lips, discrete cutaneous lesions, and gastrointestinal polyposis. Eur J Gastroenterol Hepatol 2007;19:513-7.

8. Ha M, Chung JW, Hahm KB, et al. A case of Cowden syndrome diagnosed from multiple gastric polyposis. World J Gastroenterol 2012;18:861-4.

9. Lok, C, Viseux V, Avril MF, et al. Brain magnetic resonance imaging in patients with Cowden syndrome. Medicine (Baltimore) 2005;84:129-36.

10. Tan MH, Mester JL, Ngeow J, Rybicki LA, Orloff MS, Eng C. Lifetime cancer risks in individuals with germline PTEN mutations. Clin Cancer Res 2012;18:400-7.

11. Metcalfe K, Lubinski J, Lynch HT, et al. Family history of cancer and cancer risks in women with BRCA1 or BRCA2 mutations. J Natl Cancer Inst 2010;102:1874-8. 